\title{
A comprehensive analysis of association of medical history with airflow limitation: a cross-sectional study
}

\author{
Yayoi Nishida' \\ Yasuo Takahashi' \\ Kotoe Tezuka' \\ Keiko Yamazaki \\ Yoichi Yada ${ }^{2}$ \\ Tomohiro Nakayama ${ }^{3,4}$ \\ Satoshi Asai \\ 'Division of Genomic Epidemiology \\ and Clinical Trials, Clinical Trials \\ Research Center, ${ }^{2}$ Division of \\ Pharmacology, Department of \\ Biomedical Sciences, ${ }^{3}$ Division of \\ Companion Diagnostics, ${ }^{4}$ Division \\ of Laboratory Medicine, Department \\ of Pathology and Microbiology, \\ Nihon University School of \\ Medicine, Itabashi-ku, Tokyo, Japan
}

Correspondence: Yasuo Takahashi Division of Genomic Epidemiology and Clinical Trials, Clinical Trials Research Center, Nihon University School of Medicine, 30-I Oyaguchi-Kami Machi, Itabashi-ku, Tokyo I73-86I0, Japan

Tel +8 I 339728 I II ext 2770

Fax +81359174670

Email takahashi.yasuo@nihon-u.ac.jp
This article was published in the following Dove Press journal:

International Journal of COPD

8 August 2017

Number of times this article has been viewed

Background: Multiple comorbidity is common and increases the complexity of the presentation of patients with COPD. This study was a comprehensive analysis of the relationship between a medical history of 22 disease categories and the presence of airflow limitation (AL) without any history of asthma or bronchiectasis, compatible with COPD.

Methods: A total of 11,898 Japanese patients aged $\geq 40$ years, who underwent spirometry tests, comprising patients with AL ( $n=2,309)$ or without AL $(n=9,589)$, were evaluated. Generalized estimating equations were used to assess the relationship between the presence of $\mathrm{AL}$ and each disease. The model was adjusted for age, sex, body mass index (BMI) and pack-years of smoking.

Results: In multivariate analysis, female sex (odds ratio [OR]: 0.59; 95\% confidence interval [CI]: 0.52-0.67), age (OR for 10-year age increase: 1.99; CI: 1.90-2.09), BMI (OR for $1 \mathrm{~kg} / \mathrm{m}^{2}$ increase: 0.96 ; CI: 0.95-0.98) and smoking history ( $<15$ vs $15-24,25-49$ and $\geq 50$ pack-years; OR: $1.78,2.6$ and 3.69, respectively; CI: 1.46-2.17, 2.24-3.0 and 3.15-4.33, respectively) were significantly associated with the presence of AL. In addition, a history of tuberculosis (OR: 1.72; CI: 1.39-2.11), primary lung cancer (OR: 1.50; CI: 1.28-1.77), myocardial infarction (OR: 1.22; CI: 1.01-1.48), heart failure (OR: 1.53; CI: 1.29-1.81), arrhythmia (OR: 1.19; CI: 1.03-1.38) or heart valve disorder (OR: 1.33; CI: 1.14-1.56) was significantly associated with the presence of AL, after adjustment.

Conclusion: This study suggests that a history of heart disease leading to abnormal cardiac function may be associated with AL and that the presence of certain types of heart disease provides a rationale to assess lung status and look for respiratory impairment, including COPD.

Keywords: airflow limitation, COPD, chronic heart disease, arrhythmia, heart valve disorder

\section{Introduction}

COPD is a major cause of morbidity and mortality and represents an increasing burden worldwide; it is estimated to become the third most common cause of death and the fifth most common cause of disability by the year 2020.1,2 COPD is characterized by persistent airflow limitation (AL) that is usually progressive and associated with an enhanced chronic inflammatory response in the airways and the lung to noxious particles or gases. ${ }^{3,4}$ Comorbid conditions, including cardiovascular disease, skeletal muscle dysfunction, metabolic syndrome, osteoporosis, depression and lung cancer, occur frequently in patients with COPD. ${ }^{3-5}$ The concept of a mechanism by which chronic inflammation in the lung, such as that induced in part by smoking, spreads to the blood, the so-called systemic inflammation, resulting in the damage of the other organs in patients with COPD, has been proposed. ${ }^{4,6}$ Mapel et $\mathrm{al}^{7}$ reported that patients with 
COPD had an average of 3.7 chronic comorbid conditions, whereas those without COPD had 1.8. The Global Initiative for Chronic Obstructive Lung Disease (GOLD) guidelines recommend that not only the lung status but also comorbid conditions should be assessed and treated. ${ }^{3}$ The existence of COPD may actually increase the risk for concomitant diseases, particularly lung cancer and cardiovascular disease..$^{8-10}$ On the other hand, several comorbid conditions are reported to be associated with increased COPD exacerbations and a higher risk of hospitalization, resulting in high mortality and morbidity. ${ }^{11-16}$ In recent reports, the main causes of death in mild or moderate COPD are lung cancer and cardiovascular diseases, including myocardial infarction and heart failure, whereas respiratory failure is the most common cause in severe COPD. ${ }^{17-19}$ It is increasingly recognized that many patients with COPD have comorbid conditions and that these have a major impact on their quality of life and survival. ${ }^{20}$ New findings concerning the possible association of various chronic conditions, for example, heart diseases other than myocardial infarction and heart failure, with COPD would be of interest. There is a paucity of reports providing data from a comprehensive analysis of medical history, which may be associated with COPD.

The aim of the present study was to examine the relationship between the presence of AL without any history of asthma or bronchiectasis, compatible with COPD, and a medical history of 22 categories of diseases, including cerebrovascular disease, heart disease, hypertension, diabetes mellitus, dyslipidemia, osteoporosis, depression and lung cancer, using a clinical database with spirometry data in Japan.

\section{Methods}

\section{Population}

This study was based on a cross-sectional study comprising 15,631 Japanese patients aged 40 years or older who underwent spirometry tests in Nihon University Itabashi Hospital during the period from September 2005 to December 2008. We excluded patients who had been diagnosed with asthma or bronchiectasis during or prior to the study period and those with restrictive-type pulmonary dysfunction. The remaining 11,898 patients were included in this study. The experimental protocol was approved as a clinical study by the ethics committee of Nihon University School of Medicine (NUSM).

\section{Data collection}

For each individual, information on patient demographics (age, sex, weight and height), medical history and spirometry data was collected from the NUSM Clinical Data Warehouse (CDW). This CDW is a centralized anonymous data repository that integrates detailed clinical information such as patient demographics, diagnosis, prescribing data and laboratory data from the hospital information systems of Nihon University Itabashi Hospital and is described elsewhere. ${ }^{21}$ Medical history included information on pulmonary tuberculosis (ICD-10 code, A15), malignant neoplasm (C00-C97, D00-D09), cancer of the oropharynx and trachea (C10-14, C32, C33), primary lung cancer (C34), thyroid disease (E00-E07), diabetes mellitus (E10-E14), hyperlipidemia (E78), major depressive disorder (F32, 33), essential hypertension (I10), myocardial infarction (I21, I22), other heart disease (I30-I52; including endocarditis [I30-I33], heart valve disorder [I34-I37], myocarditis and cardiomyopathy [I40-I43], arrhythmia [I44-I45, I47-I49] and heart failure [I50]), arteriosclerosis (I25, I67, I70), cerebrovascular disease (I60-I69), cerebral infarction and transient cerebral ischemic attack (G45, I63-I66), arterial thrombosis (I74), acute bronchitis (J20), pneumonia (J11-J18, $\mathrm{J} 22$, J85, J95), liver disease (K70-K77), rheumatoid arthritis (M05-M06, M08), gout (M10), osteoporosis (M80, M81) and kidney disease (N00-N19) that had been diagnosed in the period before the first date (index date) of spirometry tests. Information regarding smoking history was obtained through a questionnaire at a visit for a spirometry test and was used to classify individuals as 0-14, 15-24, 25-49, $\geq 50$ pack-years and unknown. Body mass index (BMI) at a visit for a spirometry test was calculated as weight divided by height squared $\left(\mathrm{kg} / \mathrm{m}^{2}\right)$.

\section{Spirometry}

Spirometry was performed using a CHESTAC- 8800 spirometer (Chest MI, Inc., Tokyo, Japan). All spirometry tests were performed with patients in the sitting position, wearing a nose clip and using a disposable mouthpiece. All subjects were asked to perform at least three forced vital capacity (FVC) maneuvers and slow vital capacity (VC) maneuvers, according to the recommendations of the American Thoracic Society guidelines. ${ }^{22}$ The highest forced expiratory volume in 1 second $\left(\mathrm{FEV}_{1}\right)$ and $\mathrm{FVC}$ values were recorded. A diagnosis of $\mathrm{AL}$ was defined as a $\mathrm{FEV}_{1} / \mathrm{FVC}$ $\left(\mathrm{FEV}_{1.0} \%\right)$ ratio less than $70 \%$, according to the Global Initiative for GOLD guidelines. Reference values for $\mathrm{FEV}_{1} \%$ predicted were derived from Japanese criteria. Spirometry data at the first testing in each individual were adopted for this study. Spirometry data from post-bronchodilator testing were excluded from this study, since the majority of our subjects did not undergo post-bronchodilator testing. 


\section{Statistical analysis}

Comparisons of differences in patient characteristics between groups with and without AL were performed using Student's $t$-test for continuous variables and chi-squared test for categorical data. Generalized estimating equations (GENMOD procedure in SAS software, version 9.3 [SAS Institute Inc., Cary, NC, USA]) were performed to assess the association between the presence of AL and medical history, with adjustment for potential confounding factors, including age, sex, BMI and pack-years of smoking. The use of generalized estimating equations with an independent correlation structure accounts for clustering of outcomes due to multiple hospital departments. Odds ratios (ORs) and 95\% confidence intervals (CIs) were computed. All reported $P$-values of $<0.05$ were considered to indicate statistical significance. All statistical analyses were performed with SAS software, version 9.3.

\section{Results}

Among 15,631 patients aged older than 40 years who underwent spirometry tests, 3,733 patients were excluded because they were diagnosed with asthma or bronchiectasis by physicians or displayed a restrictive abnormality on spirometry. The remaining 11,898 subjects were classified into patients with AL (AL patients; $n=2,309$ ) and without AL (non-AL patients; $n=9,589$ ) and were included in the present study. The patient characteristics of AL and non-AL patients, including medical history, are described in Table 1. In non-AL patients, mean age was 55.34 years, and $56.5 \%$ were female. AL patients were older and less likely to be female than non-AL patients; mean age was 69.06 years, and $32.9 \%$ were female. AL patients had a greater smoking history (pack-years) and lower BMI than non-AL patients.

Table I Characteristics of patients with and without AL

\begin{tabular}{|c|c|c|c|}
\hline Characteristics & $\begin{array}{l}\text { Patients without } \\
\text { AL }(n=9,589)\end{array}$ & $\begin{array}{l}\text { Patients with } \\
\text { AL }(n=2,309)\end{array}$ & $P$-value \\
\hline Age (years, mean $\pm S D)$ & $55.34 \pm 17.64$ & $69.06 \pm 10.53$ & $<0.0001$ \\
\hline Female & $5,4 \mid 4(56.5 \%)$ & $760(32.9 \%)$ & $<0.000$ I \\
\hline $\mathrm{BMI}\left(\mathrm{kg} / \mathrm{m}^{2}\right.$, mean $\left.\pm \mathrm{SD}\right)$ & $22.98 \pm 3.95$ & $22.69 \pm 3.46$ & $<0.0001$ \\
\hline Smoking history (pack-years) & & & $<0.0001$ \\
\hline $0-14$ & $6,713(70.0 \%)$ & 871 (37.7\%) & \\
\hline $15-24$ & 787 (8.2\%) & $185(8.0 \%)$ & \\
\hline $25-49$ & $1,298(13.5 \%)$ & $607(26.3 \%)$ & \\
\hline$\geq 50$ & $683(7.1 \%)$ & $610(26.4 \%)$ & \\
\hline Unknown & $108(1.2 \%)$ & $36(1.6 \%)$ & \\
\hline \multicolumn{4}{|l|}{ Medical history } \\
\hline Pulmonary tuberculosis & $319(3.3 \%)$ & $20(8.8 \%)$ & $<0.000$ I \\
\hline Malignant neoplasm & $4,802(50.1 \%)$ & $1,262(54.7 \%)$ & 0.0001 \\
\hline Cancer of oropharynx and trachea & $270(2.8 \%)$ & $106(4.6 \%)$ & $<0.0001$ \\
\hline Primary lung cancer & $573(6.0 \%)$ & $354(15.3 \%)$ & $<0.000$ I \\
\hline Thyroid disease & I,643 (I7.1\%) & $290(12.6 \%)$ & $<0.0001$ \\
\hline Diabetes mellitus & $3,944(41.1 \%)$ & $1,069(46.3 \%)$ & $<0.0001$ \\
\hline Hyperlipidemia & $1,037(10.8 \%)$ & $362(15.7 \%)$ & $<0.0001$ \\
\hline Major depressive disorder & 114 (I.2\%) & 25 (1.1\%) & 0.6700 \\
\hline Essential hypertension & $1,270(13.2 \%)$ & $503(21.8 \%)$ & $<0.0001$ \\
\hline Myocardial infarction & $44 \mathrm{I}(4.6 \%)$ & $205(8.9 \%)$ & $<0.000$ I \\
\hline Other heart disease & 938 (9.8\%) & $418(18.1 \%)$ & $<0.000$ I \\
\hline Arteriosclerosis & $635(6.6 \%)$ & $215(9.3 \%)$ & $<0.0001$ \\
\hline Cerebrovascular disease & $752(7.8 \%)$ & $256(\mid 1.1 \%)$ & $<0.0001$ \\
\hline Cerebral infarction and TIA & $568(5.9 \%)$ & $210(9.1 \%)$ & $<0.0001$ \\
\hline Arterial thrombosis & 977 (I0.2\%) & $343(14.9 \%)$ & $<0.0001$ \\
\hline Acute bronchitis & $182(1.9 \%)$ & $53(2.3 \%)$ & 0.2180 \\
\hline Pneumonia & 671 (7.0\%) & $253(11.0 \%)$ & $<0.0001$ \\
\hline Liver disease & I,992 (20.8\%) & $559(24.2 \%)$ & 0.0003 \\
\hline Rheumatoid arthritis & $620(6.5 \%)$ & $127(5.5 \%)$ & 0.0860 \\
\hline Gout & $77(0.8 \%)$ & $29(1.3 \%)$ & 0.0376 \\
\hline Osteoporosis & $365(3.8 \%)$ & $82(3.6 \%)$ & 0.5627 \\
\hline Kidney disease & I,707 (I7.8\%) & 491 (2I.3\%) & 0.0001 \\
\hline
\end{tabular}

Note: Data are numbers of individuals (\%) unless otherwise stated.

Abbreviations: AL, airflow limitation; SD, standard deviation; BMI, body mass index; TIA, transient cerebral ischemic attack. 
Table 2 Association between presence of AL and medical history

\begin{tabular}{|c|c|c|c|c|}
\hline \multirow[t]{2}{*}{ Explanatory variable } & \multicolumn{2}{|l|}{ Unadjusted } & \multicolumn{2}{|l|}{ Adjusted $^{\mathrm{a}}$} \\
\hline & OR (95\% CI) & $P$-value & OR (95\% Cl) & $P$-value \\
\hline \multicolumn{5}{|l|}{$\overline{\text { Sex }}$} \\
\hline Female & $0.38(0.34-0.42)$ & $<0.0001$ & $0.59(0.52-0.67)$ & $<0.0001$ \\
\hline Male & Reference & & Reference & \\
\hline Age (10-year age increase) & $1.95(1.87-2.03)$ & $<0.0001$ & $1.99(1.90-2.09)$ & $<0.000$ I \\
\hline BMI (I kg/m² increase) & $0.98(0.97-0.99)$ & 0.0006 & $0.96(0.95-0.98)$ & $<0.000$ I \\
\hline \multicolumn{5}{|l|}{ Smoking history (pack-years) } \\
\hline $0-14$ & Reference & & Reference & \\
\hline $15-24$ & $1.81(1.52-2.16)$ & $<0.0001$ & $1.78(1.46-2.17)$ & $<0.000$ I \\
\hline $25-49$ & $3.60(3.20-4.06)$ & $<0.0001$ & $2.60(2.24-3.00)$ & $<0.000$ I \\
\hline$\geq 50$ & $6.88(6.04-7.84)$ & $<0.0001$ & $3.69(3.15-4.33)$ & $<0.0001$ \\
\hline Unknown & $2.57(1.75-3.77)$ & $<0.0001$ & $1.92(1.28-2.88)$ & 0.0017 \\
\hline \multicolumn{5}{|l|}{ Medical history } \\
\hline \multicolumn{5}{|l|}{ Pulmonary tuberculosis } \\
\hline No & Reference & & Reference & \\
\hline Yes & $2.82(2.35-3.38)$ & $<0.0001$ & $1.72(1.39-2.11)$ & $<0.0001$ \\
\hline \multicolumn{5}{|l|}{ Primary lung cancer } \\
\hline No & Reference & & Reference & \\
\hline Yes & $2.85(2.47-3.28)$ & $<0.0001$ & $1.50(\mid .28-1.77)$ & $<0.000$ I \\
\hline \multicolumn{5}{|l|}{ Myocardial infarction } \\
\hline No & Reference & & Reference & \\
\hline Yes & $2.02(1.70-2.40)$ & $<0.0001$ & $1.22(1.01-1.48)$ & 0.0399 \\
\hline \multicolumn{5}{|l|}{ Other heart diseases } \\
\hline No & Reference & & Reference & \\
\hline Yes & $2.04(I .80-2.3 I)$ & $<0.0001$ & $1.36(1.18-1.56)$ & $<0.0001$ \\
\hline
\end{tabular}

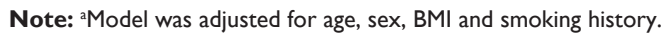

Abbreviations: AL, airflow limitation; OR, odds ratio; $\mathrm{Cl}$, confidence interval; $\mathrm{BMI}$, body mass index.

Table 2 shows the association between the presence of $\mathrm{AL}$ and medical history, which was significant. In multivariate analysis, which included age, sex, BMI and smoking history in the model, female sex (OR: $0.59 ; 95 \% \mathrm{CI}$ : 0.52-0.67), age (OR for 10-year age increase: $1.99 ; 95 \%$ CI: $1.90-2.09)$, BMI (OR for $1 \mathrm{~kg} / \mathrm{m}^{2}$ increase: 0.96 ; $95 \%$ CI: $0.95-0.98)$ and smoking history ( $<15$ vs $15-24,25-49$ and $\geq 50$ pack-years; OR: $1.78,2.6$ and 3.69 , respectively; 95\% CI: $1.46-2.17,2.24-3.0$ and 3.15-4.33, respectively) were significantly associated with the presence of AL. After adjustment for age, sex, BMI and smoking history, a history of tuberculosis (OR: 1.72; 95\% CI: 1.39-2.11), primary lung cancer (OR: 1.50 ; 95\% CI: 1.28-1.77), myocardial infarction (OR: 1.22; 95\% CI: 1.01-1.48) or other heart disease (OR: 1.36 ; $95 \%$ CI: $1.18-1.56)$ was associated with the presence of AL. There was no significant association between all other medical history and AL. We have included non-significant data in Table S1.

We further examined the association between the presence of AL and a history of other heart diseases, which included five subcategories: endocarditis, heart valve disorder, myocarditis and cardiomyopathy, arrhythmia and heart failure (Table 3). After adjustment for age, sex, BMI and smoking history, heart valve disorder (OR: 1.33; 95\% CI: 1.14-1.56),

Table 3 Subcategories of other heart diseases associated with the presence of $A L$

\begin{tabular}{|c|c|c|c|c|c|c|}
\hline \multirow[t]{2}{*}{ Explanatory variable } & \multirow{2}{*}{$\begin{array}{l}\text { Patients without } \\
\text { AL }(n=9,589) \\
n(\%)\end{array}$} & \multirow{2}{*}{$\begin{array}{l}\text { Patients with } \\
\text { AL }(n=2,309)\end{array}$} & \multicolumn{2}{|l|}{ Unadjusted } & \multicolumn{2}{|l|}{ Adjusted $^{a}$} \\
\hline & & & OR (95\% Cl) & $P$-value & OR (95\% CI) & $P$-value \\
\hline Endocarditis & $33(0.3)$ & $10(0.4)$ & $1.25(0.62-2.56)$ & 0.5235 & $0.92(0.40-2.14)$ & 0.8485 \\
\hline Heart valve disorder & $706(7.4)$ & $296(12.8)$ & $1.85(1.60-2.14)$ & $<0.000$ I & $1.33(1.14-1.56)$ & 0.0004 \\
\hline Myocarditis and cardiomyopathy & $57(0.6)$ & $16(0.7)$ & $1.17(0.69-2.04)$ & 0.5967 & $1.02(0.56-1.86)$ & 0.9614 \\
\hline Arrhythmia & $892(9.3)$ & $359(15.6)$ & $1.79(1.57-2.05)$ & $<0.000$ I & $1.19(1.03-1.38)$ & 0.0217 \\
\hline Heart failure & $528(5.5)$ & $274(11.9)$ & $2.31(1.98-2.69)$ & $<0.0001$ & $1.53(1.29-1.81)$ & $<0.000$ I \\
\hline
\end{tabular}

Note: Model was adjusted for age, sex, BMI and smoking history.

Abbreviations: $\mathrm{AL}$, airflow limitation; $\mathrm{OR}$, odds ratio; $\mathrm{Cl}$, confidence interval; $\mathrm{BMI}$, body mass index. 
arrhythmia (OR: 1.19; 95\% CI: 1.03-1.38) and heart failure (OR: 1.53 ; 95\% CI: 1.29-1.81) were significantly associated with the presence of AL. The association of AL with endocarditis and myocarditis was not significant, which, however, may not have been adequately evaluated because of the small number of patients with these conditions.

\section{Discussion}

In the present study, we examined the association between the presence of AL compatible with COPD and medical history and found that a history of tuberculosis or primary lung cancer was significantly associated with AL. In addition, we found that a history of myocardial infarction, heart failure, arrhythmia or heart valve disorder was significantly associated with AL. These findings suggest that a history of heart disease leading to an abnormality of cardiac function may be associated with AL.

It is well recognized that lung cancer and cardiovascular disease, including congestive heart failure and ischemic heart disease, are major comorbid conditions most closely linked to COPD. ${ }^{9,12,23,24}$ The reasons for these links are not fully understood, but they may be related to spread of "systemic inflammation" from chronic inflammation in the lung, induced in part by noxious particles or gases (eg, from smoking). ${ }^{3,4}$ Smoking is still the major risk factor for lung cancer, cardiovascular disease and COPD. In the present study, we identified a significant association between the presence of AL and medical history, including lung cancer, myocardial infarction and heart failure, even after adjustment for covariates of age, sex, BMI and smoking history. As expected, these findings, which were consistent with previous reports, are reasonable. An interesting new finding in the present study is that a history of arrhythmia or heart valve disorder was associated with the presence of AL. These relationships were significant even after adjustment for smoking history, although their links were weak. The underlying mechanism of these links between AL and chronic heart diseases, including arrhythmia and heart valve disorder, is not clear. However, heart attacks, heart valve disorders and arrhythmias, which can lead to damage or weakness of the heart, can cause heart failure. In addition, shortness of breath, which is known as dyspnea, is one of the central features of these heart diseases and COPD. The degree of dyspnea varies with the severity of COPD, these heart diseases and their combinations. There is a possibility that these links, in which COPD and these heart diseases themselves interact together, may exist not only for symptoms but also for risk factors or causality for developing diseases. Supporting this, Carson et $\mathrm{al}^{25}$ reported that the presence of ventricular arrhythmia (OR: 1.91, 95\% CI: 1.10-3.31) and atrial fibrillation (OR: 2.27, 95\% CI: 1.14-4.51) were independent predictors of 1-year mortality, suggesting that indicators of heart dysfunction could be important predictors of increased risk of COPD mortality. However, clarifying the complexity of these links could be challenging.

Regarding other medical history, diabetes mellitus, hyperlipidemia, depression, hypertension, arteriosclerosis and osteoporosis are common comorbid conditions in COPD and are systemic features associated with COPD, which may be related to "systemic inflammation", 3,4,12,26,27 In the present study, a history of diabetes mellitus, hyperlipidemia, depression, hypertension, arteriosclerosis or osteoporosis was not associated with AL in multivariate analysis, whereas the relationships with these diseases except for osteoporosis were significant before adjustment (Table S1). These findings suggest that valid evaluation of the links between COPD and these chronic diseases, which would be trivial under the influence of covariates such as smoking history and age, could be difficult. The discrepancy between the present study and previous studies may be explained in part by differences in the experimental design or the study population (described in the "Limitation" section). Owing to the nature of the university hospital, many referred patients in our hospital have more advanced disease and need advanced therapy. Thus, this study may have underestimated the prevalence of the early stages of these chronic diseases, which may influence our findings.

\section{Limitations}

Our study has some potential limitations. We selected the study subjects from patients who underwent spirometry tests in our university hospital. Because execution of a spirometry test is not practical for patients with severe general conditions and/or the acute phase of certain diseases, such as acute myocardial infarction or acute heart failure, this study may systematically underestimate the prevalence of these diseases, especially in the recent period prior to the date of their spirometry tests. Furthermore, pulmonary function status is frequently assessed as a preoperative examination, which may account for the higher prevalence of cancers in this study population than in the general population. Thus, the prevalence of past diseases in this study population would be different from that in the general population, potentially limiting the ability to generalize the results. In addition, this study included only Japanese patients. We, therefore, should consider the possibility that racial differences in genetic 
variations, eg, a variant in the $\alpha 5$ nicotinic acetylcholine receptor subunit gene, which has been identified to be associated with lung cancer and COPD, may impact on the results of this study. ${ }^{28,29}$ Recently, an international worldwide study in the Burden of Obstructive Lung Disease (BOLD) project reported a significant association between spirometrically defined COPD and its risk factors - age (OR: 1.52/10 years), BMI (OR: 0.50 in obese compared with normal weight), education level ( 0.76 per stage of education completed), passive cigarette smoke exposure (OR: 1.24) and tuberculosis (OR: 1.78) - after adjusting for pack-years of smoking. ${ }^{30}$ In addition, another international BOLD study showed that chronic AL was associated with lower BMI, after adjusting for age, sex, smoking and between-site heterogeneity. ${ }^{31}$ Similarly, the present study showed that AL was associated with age, BMI, tuberculosis and pack-years of smoking even after adjustment. These findings may suggest acceptable validity of this study population and analysis and that it is appropriate to generalize the findings of this study population, in spite of it containing only Japanese patients. Second, patients who were diagnosed with asthma or bronchiectasis were excluded from analyses, because these conditions could impact on the spirometry results. This study may have underestimated the prevalence of AL. Third, we could not examine the impact of socioeconomic factors, eg, occupation, income or education status, on AL because these data are not available in the NUSM CDW. We should consider the possibility that socioeconomic factors may have influenced the results of this study. Fourth, spirometry data were collected from the hospital information systems, including all departments in our hospital. There is a possibility that outcomes data may not be independent because the data collected from the same department are likely to be correlated. Therefore, we used generalized estimating equations to account for the correlation of these data and to obtain valid results. Finally, whether a history of chronic heart disease, which was observed in this study, contributes to increased risk of COPD is of interest. However, the nature of the crosssectional study involved inherent issues of its limited ability to provide valid conclusions about possible causality, and it cannot precisely answer whether a past chronic disease preceded AL or was a consequence of the disease. In the present study, we assessed the medical history prior to the first date of a spirometry test, but did not assess pulmonary function status before the date of diagnosis because there were few cases with longitudinal spirometry data. The chronological order between onset of AL and past disease is clinically vague. Therefore, we did not accept the period since diagnosis to the date of spirometry tests as the disease duration and did not estimate its effect in this analysis. However, the possibility that the factor of true disease duration would influence the results of this study cannot be ruled out. The findings of our study call for further studies, such as longitudinal cohort studies for a long-term period and randomized clinical trials, for confirmation.

\section{Conclusion}

In summary, a significant relationship between the presence of AL and a history of tuberculosis or primary lung cancer was found in this and other studies. In addition, this study identified that a history of heart disease, including myocardial infarction, heart failure, arrhythmia and heart valve disorder, was significantly associated with the presence of AL. These findings suggest that the presence of these types of heart diseases provides a rationale to assess the lung status and look for respiratory impairment, including COPD.

\section{Acknowledgment}

This work was supported by the Health Sciences Research Institute, Inc., Yokohama, Japan and Convergence CT Japan KK., Tokyo, Japan.

\section{Author contributions}

YT designed the study; contributed to data acquisition, analysis and interpretation and supervised the study. YN also contributed to study design and data analysis. All authors contributed to data acquisition and interpretation, critically revised the manuscript and approved the final version to be published.

\section{Disclosure}

The authors report no conflicts of interest in this work.

\section{References}

1. Lopez AD, Shibuya K, Rao C, et al. Chronic obstructive pulmonary disease: current burden and future projections. Eur Respir J. 2006;27(2): 397-412.

2. Murray CJ, Lopez AD. Alternative projections of mortality and disability by cause 1990-2020: Global Burden of Disease study. Lancet. 1997;349(9064):1498-1504.

3. Vestbo J, Hurd SS, Agusti AG, et al. Global strategy for the diagnosis, management, and prevention of chronic obstructive pulmonary disease: GOLD executive summary. Am J Respir Crit Care Med. 2013; 187(4):347-365.

4. Fabbri LM, Luppi F, Beghe B, Rabe KF. Complex chronic comorbidities of COPD. Eur Respir J. 2008;31(1):204-212.

5. Smith MC, Wrobel JP. Epidemiology and clinical impact of major comorbidities in patients with COPD. Int J Chron Obstruct Pulmon Dis. 2014;9:871-888.

6. Fabbri LM, Rabe KF. From COPD to chronic systemic inflammatory syndrome? Lancet. 2007;370(9589):797-799. 
7. Mapel DW, Hurley JS, Frost FJ, Petersen HV, Picchi MA, Coultas DB. Health care utilization in chronic obstructive pulmonary disease. A case-control study in a health maintenance organization. Arch Intern Med. 2000;160(17):2653-2658.

8. Skillrud DM, Offord KP, Miller RD. Higher risk of lung cancer in chronic obstructive pulmonary disease. A prospective, matched, controlled study. Ann Intern Med. 1986;105(4):503-507.

9. Feary JR, Rodrigues LC, Smith CJ, Hubbard RB, Gibson JE. Prevalence of major comorbidities in subjects with COPD and incidence of myocardial infarction and stroke: a comprehensive analysis using data from primary care. Thorax. 2013;65(11):956-962.

10. Decramer M, Janssens W, Miravitlles M. Chronic obstructive pulmonary disease. Lancet. 2012;379(9823):1341-1351.

11. Roberts CM, Stone RA, Lowe D, Pursey NA, Buckingham RJ. Comorbidities and 90-day outcomes in hospitalized COPD exacerbations. COPD. 2011;8(5):354-361.

12. Mannino DM, Thorn D, Swensen A, Holguin F. Prevalence and outcomes of diabetes, hypertension and cardiovascular disease in COPD Eur Respir J. 2008;32(4):962-969.

13. Hurst JR, Vestbo J, Anzueto A, et al; Evaluation of COPD Longitudinally to Identify Predictive Surrogate Endpoints (ECLIPSE) Investigators. Susceptibility to exacerbation in chronic obstructive pulmonary disease. N Engl J Med. 2010;363(12):1128-1138.

14. Laurin C, Moullec G, Bacon SL, Lavoie KL. Impact of anxiety and depression on chronic obstructive pulmonary disease exacerbation risk. Am J Respir Crit Care Med. 2012;185(9):918-923.

15. Rizkallah J, Man SF, Sin DD. Prevalence of pulmonary embolism in acute exacerbations of COPD: a systematic review and metaanalysis. Chest. 2009;135(3):786-793.

16. Wells JM, Dransfield MT. Pathophysiology and clinical implications of pulmonary arterial enlargement in COPD. Int J Chron Obstruct Pulmon Dis. 2013;8:509-521.

17. Sin DD, Anthonisen NR, Soriano JB, Agusti AG. Mortality in COPD: role of comorbidities. Eur Respir J. 2006;28(6):1245-1257.

18. Anthonisen NR, Skeans MA, Wise RA, et al; Lung Health Study Research Group. The effects of a smoking cessation intervention on 14.5-year mortality: a randomized clinical trial. Ann Intern Med. 2005;142(4):233-239.
19. Berry CE, Wise RA. Mortality in COPD: causes, risk factors, and prevention. COPD. 2010;7(5):375-382.

20. Barnes PJ, Celli BR. Systemic manifestations and comorbidities of COPD. Eur Respir J. 2009;33(5):1165-1185.

21. Takahashi Y, Nishida Y, Asai S. Utilization of health care databases for pharmacoepidemiology. Eur J Clin Pharmacol. 2012;68(2):123-129.

22. Society AT. Standardization of spirometry, 1994 update. American Thoracic Society. Am J Respir Crit Care Med. 1995;152(3):1107-1136.

23. Young RP, Hopkins RJ, Christmas T, Black PN, Metcalf P, Gamble GD. COPD prevalence is increased in lung cancer, independent of age, sex and smoking history. Eur Respir J. 2009;34(2):380-386.

24. Finkelstein J, Cha E, Scharf SM. Chronic obstructive pulmonary disease as an independent risk factor for cardiovascular morbidity. Int J Chron Obstruct Pulmon Dis. 2009;4:337-349.

25. Carson JL, Terrin ML, Duff A, Kelley MA. Pulmonary embolism and mortality in patients with COPD. Chest. 1996;110(5):1212-1219.

26. Panagioti M, Scott C, Blakemore A, Coventry PA. Overview of the prevalence, impact, and management of depression and anxiety in chronic obstructive pulmonary disease. Int J Chron Obstruct Pulmon Dis. 2014; 9:1289-1306.

27. Inoue D, Watanabe R, Okazaki R. COPD and osteoporosis: links, risks, and treatment challenges. Int J Chron Obstruct Pulmon Dis. 2016;11 637-648.

28. Pillai SG, Ge D, Zhu G, et al; ICGN Investigators. A genomewide association study in chronic obstructive pulmonary disease (COPD): identification of two major susceptibility loci. PLoS Genet. 2009;5(3):e1000421.

29. Young RP, Hopkins RJ, Hay BA, Epton MJ, Black PN, Gamble GD. Lung cancer gene associated with COPD: triple whammy or possible confounding effect? Eur Respir J. 2008;32(5):1158-1164.

30. Hooper R, Burney P, Vollmer WM, et al. Risk factors for COPD spirometrically defined from the lower limit of normal in the BOLD project. Eur Respir J. 2012;39(6):1343-1353.

31. Vanfleteren LE, Lamprecht B, Studnicka M, et al. Body mass index and chronic airflow limitation in a worldwide population-based study. Chron Respir Dis. 2016;13(2):90-101. 


\section{Supplementary material}

Table SI Association between presence of $A L$ and medical history of 22 disease categories

\begin{tabular}{|c|c|c|c|c|}
\hline \multirow[t]{2}{*}{ Explanatory variable } & \multicolumn{2}{|l|}{ Unadjusted } & \multicolumn{2}{|l|}{ Adjusted $^{\mathrm{a}}$} \\
\hline & OR $(95 \% \mathrm{Cl})$ & $P$-value & OR $(95 \% \mathrm{CI})$ & $P$-value \\
\hline \multicolumn{5}{|l|}{ Sex } \\
\hline Female & $0.38(0.34-0.42)$ & $<0.0001$ & $0.59(0.52-0.67)$ & $<0.000 \mathrm{I}$ \\
\hline Male & Reference & & Reference & \\
\hline Age (10-year age increase) & $1.95(1.87-2.03)$ & $<0.0001$ & $1.99(1.90-2.09)$ & $<0.000$ I \\
\hline BMI (I kg/m² increase) & $0.98(0.97-0.99)$ & 0.0006 & $0.96(0.95-0.98)$ & $<0.0001$ \\
\hline \multicolumn{5}{|l|}{ Smoking history (pack-years) } \\
\hline $0-14$ & Reference & & Reference & \\
\hline $15-24$ & $1.81(1.52-2.16)$ & $<0.0001$ & $1.78(1.46-2.17)$ & $<0.0001$ \\
\hline $25-49$ & $3.60(3.20-4.06)$ & $<0.0001$ & $2.60(2.24-3.00)$ & $<0.000 \mathrm{I}$ \\
\hline$\geq 50$ & $6.88(6.04-7.84)$ & $<0.0001$ & $3.69(3.15-4.33)$ & $<0.0001$ \\
\hline Unknown & $2.57(1.75-3.77)$ & $<0.0001$ & $1.92(1.28-2.88)$ & 0.0017 \\
\hline \multicolumn{5}{|l|}{ Medical history } \\
\hline \multicolumn{5}{|l|}{ Pulmonary tuberculosis } \\
\hline No & Reference & & Reference & \\
\hline Yes & $2.82(2.35-3.38)$ & $<0.0001$ & $1.72(1.39-2.11)$ & $<0.0001$ \\
\hline \multicolumn{5}{|l|}{ Malignant neoplasm } \\
\hline No & Reference & & Reference & \\
\hline Yes & $1.20(1.10-1.32)$ & $<0.0001$ & $0.91(0.82-1.01)$ & 0.0700 \\
\hline \multicolumn{5}{|c|}{ Cancer of oropharynx and trachea } \\
\hline No & Reference & & Reference & \\
\hline Yes & $1.66(1.32-2.09)$ & $<0.0001$ & $\mathrm{I} .08(0.84-\mathrm{I} .40)$ & 0.5380 \\
\hline \multicolumn{5}{|l|}{ Primary lung cancer } \\
\hline No & Reference & & Reference & \\
\hline Yes & $2.85(2.47-3.28)$ & $<0.0001$ & $1.50(1.28-1.77)$ & $<0.000$ I \\
\hline \multicolumn{5}{|l|}{ Thyroid disease } \\
\hline No & Reference & & Reference & \\
\hline Yes & $0.69(0.6 \mathrm{I}-0.79)$ & $<0.0001$ & $1.02(0.88-1.18)$ & 0.8025 \\
\hline \multicolumn{5}{|l|}{ Diabetes mellitus } \\
\hline No & Reference & & Reference & \\
\hline Yes & $1.23(1.13-1.35)$ & $<0.0001$ & $0.91(0.82-1.00)$ & 0.0600 \\
\hline \multicolumn{5}{|l|}{ Hyperlipidemia } \\
\hline No & Reference & & Reference & \\
\hline Yes & $1.53(1.35-1.75)$ & $<0.0001$ & I.II (0.96-I.29) & 0.1446 \\
\hline \multicolumn{5}{|l|}{ Major depressive disorder } \\
\hline No & Reference & & Reference & \\
\hline Yes & $0.91(0.59-1.4 I)$ & 0.6701 & $0.8 I(0.5 I-I .29)$ & 0.3754 \\
\hline \multicolumn{5}{|l|}{ Essential hypertension } \\
\hline No & Reference & & Reference & \\
\hline Yes & $1.82(1.63-2.05)$ & $<0.0001$ & I.I $(0.96-1.25)$ & 0.1597 \\
\hline \multicolumn{5}{|l|}{ Myocardial infarction } \\
\hline No & Reference & & Reference & \\
\hline Yes & $2.02(1.70-2.40)$ & $<0.0001$ & $1.22(1.01-1.48)$ & 0.0399 \\
\hline \multicolumn{5}{|l|}{ Other heart diseases } \\
\hline No & Reference & & Reference & \\
\hline Yes & $2.04(|.80-2.3|)$ & $<0.0001$ & $1.36(1.18-1.56)$ & $<0.000$ I \\
\hline \multicolumn{5}{|l|}{ Arteriosclerosis } \\
\hline No & Reference & & Reference & \\
\hline Yes & $1.45(1.23-1.70)$ & $<0.0001$ & $1.08(0.90-1.30)$ & 0.3945 \\
\hline \multicolumn{5}{|l|}{ Cerebrovascular disease } \\
\hline No & Reference & & Reference & \\
\hline Yes & $1.47(1.26-1.70)$ & $<0.0001$ & $0.94(0.79-I .1 I)$ & 0.4517 \\
\hline
\end{tabular}


Table SI (Continued)

\begin{tabular}{|c|c|c|c|c|}
\hline \multirow[t]{2}{*}{ Explanatory variable } & \multicolumn{2}{|l|}{ Unadjusted } & \multicolumn{2}{|l|}{ Adjusted $^{a}$} \\
\hline & OR (95\% Cl) & $P$-value & OR (95\% Cl) & $P$-value \\
\hline \multicolumn{5}{|c|}{ Cerebral infraction and TIA } \\
\hline No & Reference & & Reference & \\
\hline Yes & $1.59(1.35-1.87)$ & $<0.0001$ & $0.96(0.80-1.15)$ & 0.6542 \\
\hline \multicolumn{5}{|l|}{ Arterial thrombosis } \\
\hline No & Reference & & Reference & \\
\hline Yes & $1.54(1.35-1.76)$ & $<0.0001$ & I. $12(0.97-1.30)$ & 0.1291 \\
\hline \multicolumn{5}{|l|}{ Acute bronchitis } \\
\hline No & Reference & & Reference & \\
\hline Yes & $1.21(0.89-1.65)$ & 0.2187 & I.I (0.76-I.55) & 0.5769 \\
\hline \multicolumn{5}{|l|}{ Pneumonia } \\
\hline No & Reference & & Reference & \\
\hline Yes & $1.64(1.40-1.90)$ & $<0.0001$ & $1.15(0.96-1.37)$ & 0.1254 \\
\hline \multicolumn{5}{|l|}{ Liver disease } \\
\hline No & Reference & & Reference & \\
\hline Yes & $1.22(1.09-1.36)$ & 0.0003 & $0.98(0.87-1.10)$ & 0.7210 \\
\hline \multicolumn{5}{|l|}{ Rheumatoid arthritis } \\
\hline No & Reference & & Reference & \\
\hline Yes & $0.84(0.69-1.02)$ & 0.0863 & $0.94(0.76-1.17)$ & 0.6052 \\
\hline \multicolumn{5}{|l|}{ Gout } \\
\hline No & Reference & & Reference & \\
\hline Yes & $\mathrm{I} .57(\mathrm{I} .02-2.4 \mathrm{I})$ & 0.0392 & $\mathrm{I} .04(0.63-\mathrm{I} .7 \mathrm{I})$ & 0.8830 \\
\hline \multicolumn{5}{|l|}{ Osteoporosis } \\
\hline No & Reference & & Reference & \\
\hline Yes & $0.93(0.73-1.19)$ & 0.5628 & $0.97(0.74-1.26)$ & 0.8073 \\
\hline \multicolumn{5}{|l|}{ Kidney disease } \\
\hline No & Reference & & Reference & \\
\hline Yes & $1.25(1.11-1.40)$ & 0.0001 & $1.01(0.89-1.14)$ & 0.9361 \\
\hline
\end{tabular}

Note: aModel was adjusted for age, sex, BMI and smoking history.

Abbreviations: $\mathrm{AL}$, airflow limitation; OR, odds ratio; $\mathrm{Cl}$, confidence interval; $\mathrm{BMI}$, body mass index; TIA, transient cerebral ischemic attack.

\section{Publish your work in this journal}

The International Journal of COPD is an international, peer-reviewed journal of therapeutics and pharmacology focusing on concise rapid reporting of clinical studies and reviews in COPD. Special focus is given to the pathophysiological processes underlying the disease, intervention programs, patient focused education, and self management protocols.

\section{Dovepress}

This journal is indexed on PubMed Central, MedLine and CAS. The manuscript management system is completely online and includes a very quick and fair peer-review system, which is all easy to use. Visit http://www.dovepress.com/testimonials.php to read real quotes from published authors. 